\title{
Microprocessor-based Signaling Device to Carbon Monoxide Control
}

\author{
Sviatoslav Chernetskyi \\ Specialized Computer System Dpt., \\ Lviv Polytechnic National University, \\ Lviv, Ukraine \\ e-mail: Sviatoslav1997@ukr.net \\ Andrii Slavytiak \\ Specialized Computer System Dpt., \\ Lviv Polytechnic National University, \\ Lviv, Ukraine \\ e-mail: andriy.slavityak@gmail.com
}

\author{
Roman Dunets \\ Specialized Computer System Dpt., \\ Lviv Polytechnic National University, \\ Lviv, Ukraine \\ e-mail: roman.b.dunets@lpnu.ua
}

\author{
Halyna Klym \\ Specialized Computer System Dpt., \\ Lviv Polytechnic National University, \\ Lviv, Ukraine \\ e-mail:klymha@yahoo.com
}

\begin{abstract}
Microprocessor-based signaling device of carbon monoxide presence using sensor of carbon monoxide were realized on specialized system on a chip. The following parameters are: the sensitivity of the sensor carbon monoxide at least $30 \mathrm{ppm}$; the number of measuring channels - 2; supply voltage $-+5 \mathrm{~V}$.
\end{abstract}

Index Terms-Signaling device; carbon monoxide, presence; microprocessor.

\section{INTRODUCTION}

In the modern world it is almost impossible to imagine a comfortable life without gas supply in the house. Using of gasoperated devices allows us to heat the premises, cook food, and provide the home with hot water. And all these devices can be potentially dangerous - a possible leak of gas that can cause a fire or poisoning of people. To prevent such cases, need to install the gas detectors - devices for controlling the level of combustible gases in the air. Devices announce the leak of sound and light signals that can save lives, people's health and property.

Chondrogen gas (carbon monoxide) is a colorless, odorless, poisonous gas $[1,2]$. It is formed during combustion in the absence of oxygen. For example, if there is no proper access to fresh air in the room, chimneys are closed and ventilation is bad, carbon monoxide may be collected there. In addition, strong wind can cause reciprocation in the ventilation and chimney stack, and because of this, combustion products will not be output outside and accumulate indoors.

Chondrogen gas is dangerous because when it enters the blood it forms with a hemoglobin of blood a fairly stable compound - Carbaminohemoglobin [3]. As a result the blood becomes incapable of transmitting oxygen to the human body. Therefore, a person dies, as a result of strangulation.

The dangerous concentration of carbon monoxide in the air is $0.05 \%$. Symptoms such as: deterioration of color and light sensitivity of vision; hearing impairment; headache; feeling of pressure. At high concentrations of gas there is a severe headache, weakness, dizziness, nausea.

The aim of this work is development of microprocessorbased signaling device to control the level of carbon monoxide in the air.

\section{MICROPROCESSOR BASED SIGNALING DEVICE}

To implement a microprocessor based signaling device of carbon monoxide presence, you need a microcontroller [4,5] to which you can connect several different devices. It should have reset and Clock System for initial reset and synchronization, respectively. The signals from the sensors come to the microcontroller through the connectors.

To measure the level of carbon monoxide $(\mathrm{CO})$ it is necessary to use a special sensor [6], which will be very sensitive to the level of $\mathrm{CO}$ in the air, because even $0.05 \%$ of carbon monoxide in the air is dangerous to human health.

To send a text message the GSM module should be used $[7,8]$ This module should work in all ranges of GSM and be able to send a predetermined message to the specified number. To do this, it must have a SIM card installed.

The block diagram of the device is shown in Fig.1.

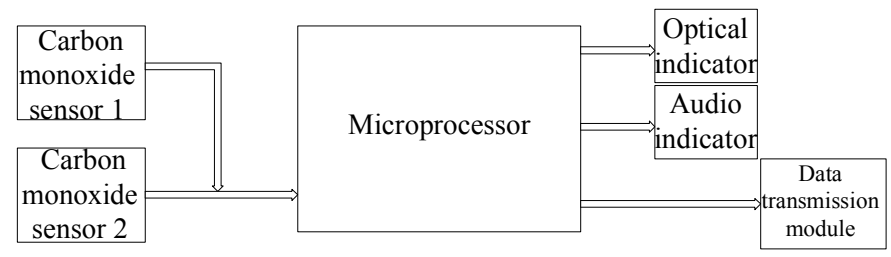

Fig. 1. The block diagram of the device

The main element of the device is Cypress Microcontroller CY8C4245AXI-483 $[9,10]$. It provides the interaction of all 
components of the system. Most microcontroller contacts have several functional assignments. For contacts, you can set the type of "input" or "output", for reading or writing any data. Fig. 2 depicts the functional scheme of connecting sensors to the microcontroller.

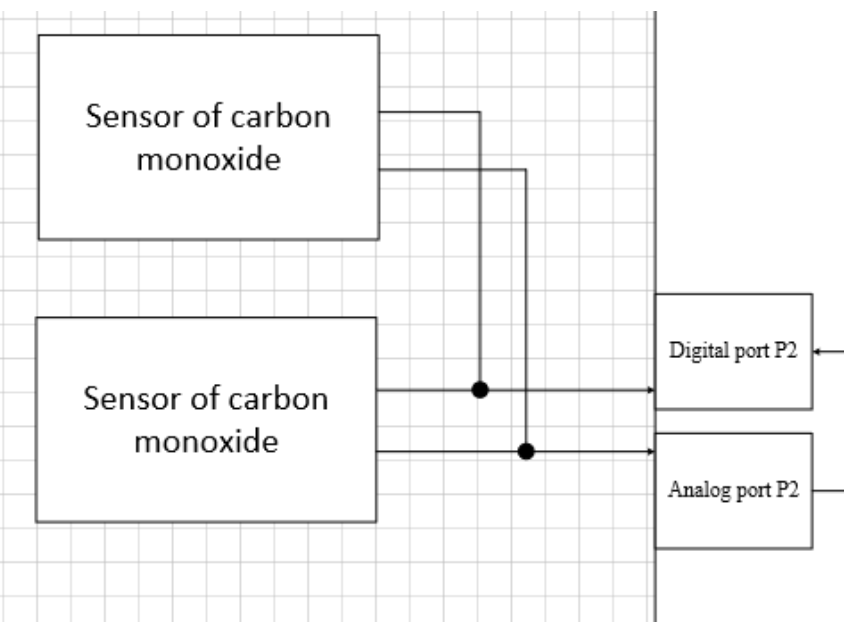

Fig. 2. Functional scheme of connecting sensors.

To connect the sensors of carbon monoxide it is necessary to use two input ports: one digital and one analog. Because microcontroller can not process analog data, all information from the analog port is first received in the ADC, and only then it enters the microprocessor.

In order to device to inform people of danger, it is necessary to connect audio and optical indicators to it. The functional scheme of connecting the audio indicator to the microcontroller is shown in Fig. 3.

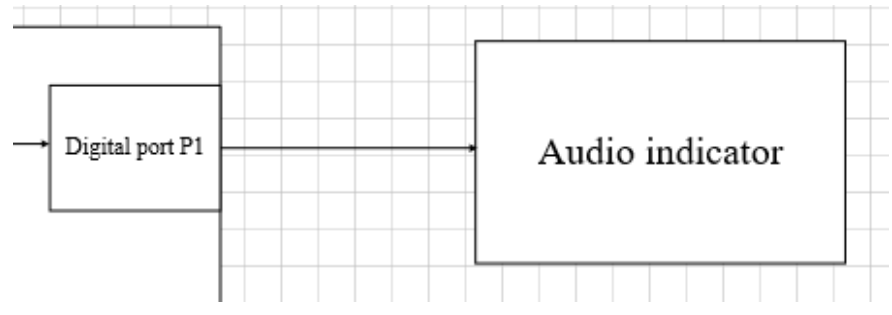

Fig. 3. Functional scheme of connecting audio indicator.

To connect the audio indicator you should use the digital port P1. Through this port, an electrical voltage will be applied to the sound indicator (piezo dynamic), which will be transmitted to the oscillation of the membrane. These vibrations create a sound (a sound wave).

Functional scheme of connection of a light indicator is shown in Fig. 4.

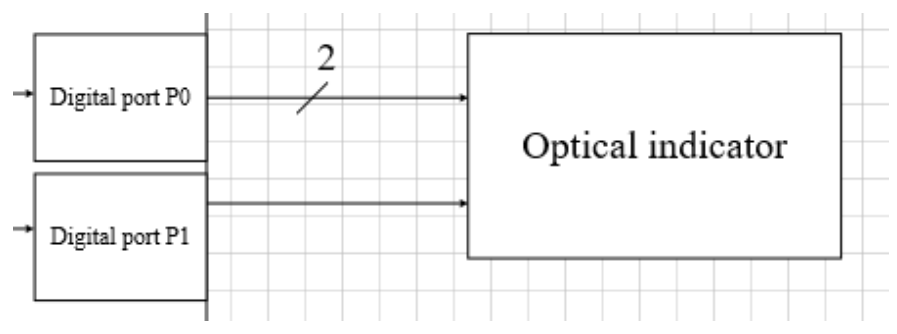

Fig. 4. Functional scheme of connecting optical indicator.
As an optical indicator, 3 LEDs will be used. These LEDs emit incoherent light when passing through them an electric current. That is why you need to use 3 digital ports to connect the LEDs to the microcontroller.

As an additional notification method, you need to use the GSM module. The functional scheme of connecting the GSMmodule is shown in Fig.5.

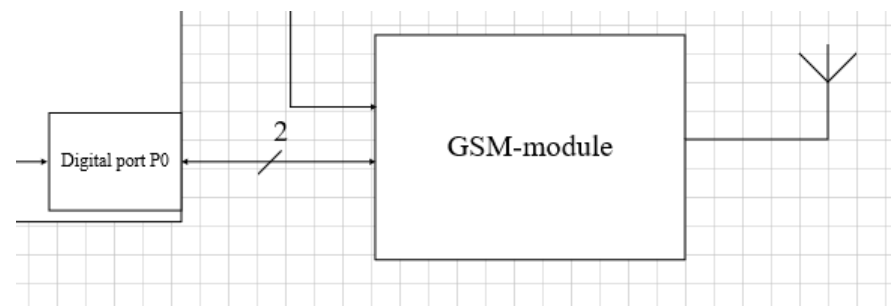

Fig. 5. Functional scheme of connecting GSM-module.

The GSM module connects to the microcontroller by UART. That is why you need to use two digital ports (TX and $\mathrm{RX}$ ) to connect. The TX port is designed to send data to the GSM module, and RX to receive data.

UART (Universal Asunhronous Receiver / Transmitter) is a universal asynchronous receiver / transmitter, a digital interface for data communication in a sequential form. It is very common and demanded, it has hardware implementation in many microcontrollers.

The UART can be used to interact components within a single device, or to connect devices with each other. For external connections, signals with TTL or CMOS logic levels are poorly suited due to low impedance. The common physical layer standard for a UART that is suitable for connecting external devices is the RS-232. This standard, in particular, corresponds to the serial port (COM port) of your computer. Therefore, the microcontroller with the help of the level conversion scheme can exchange information with the COM port of the computer.

The functional diagram of the controller is shown in Fig. 6. The main resonator generates a synchronization signal for the analog and digital peripherals. It provides a clock-stable pulse source. The resonator is connected to the input terminal XTAL0 and the output XTAL1. The standard frequency of the resonator is $24 \mathrm{MHz}$.

Cypress AN205148 quartz with a frequency of $24 \mathrm{MHz}$ is used to implement synchronization. Resetting the microcontroller can be implemented in several ways, including software reset. The XRES port is reserved for an external reset to avoid configuration problems. The XRES port has an internal resistor that is always turned on. To implement the reset, you need to provide a logical zero to this port.

To provide the power controller, two different voltages are required: $+3.3 \mathrm{~V}$ and $+5 \mathrm{~V}$. The voltage of $5 \mathrm{~V}$ is fed through an X1-type USB Mini B connector from an external source.

The input voltage is regulated by a downward power supply to $3.3 \mathrm{~V}$. As a result, we obtain the output voltage VBUS (5 V) and $3.3 \mathrm{~V}$. 


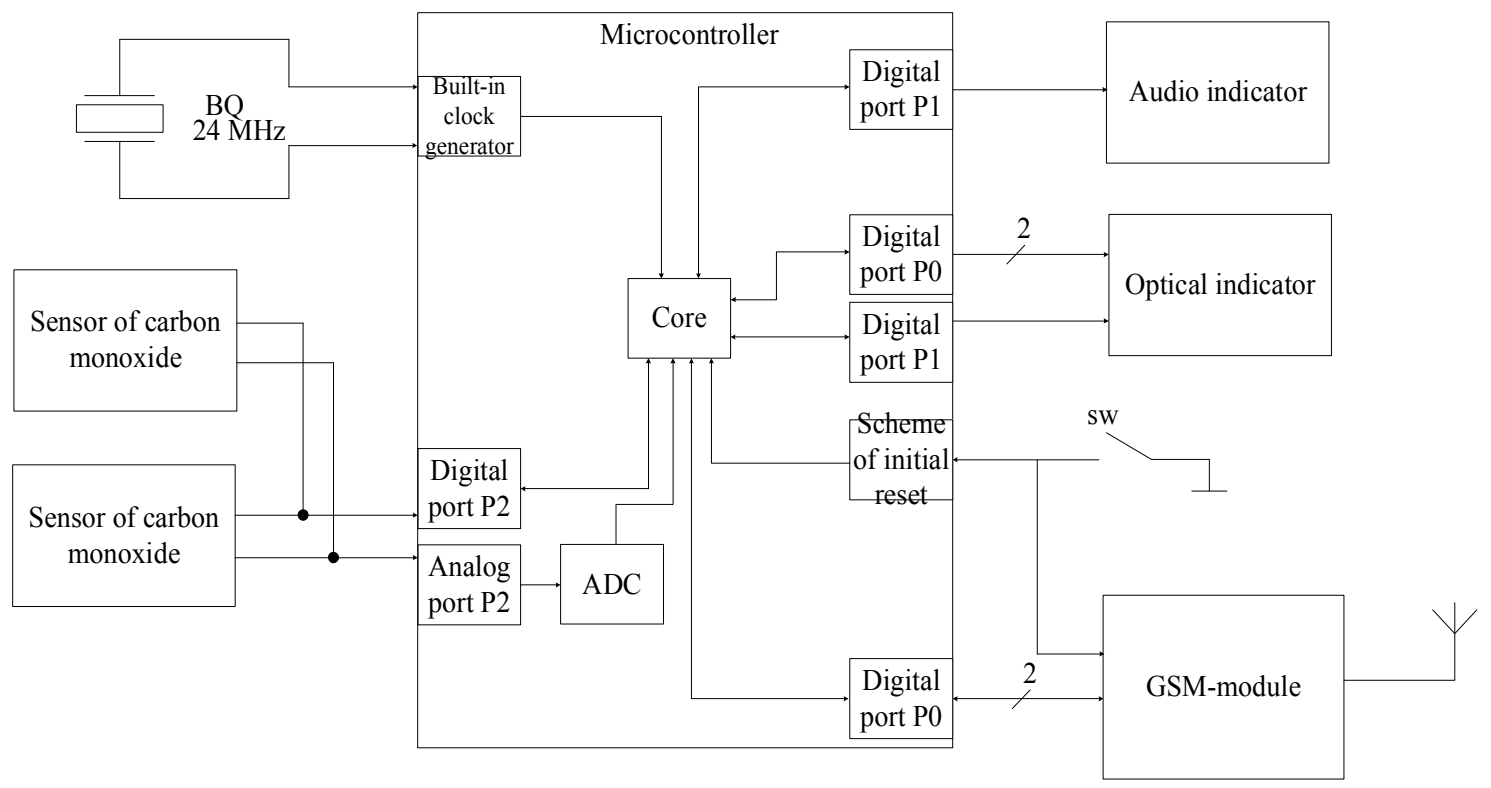

Fig. 6. Functional diagram of the controller.

In order to provide the power to the GSM module, a lowering power supply must be used additionally. It connects to a voltage of $5 \mathrm{~V}$ and at the output we get a voltage of $3.8 \mathrm{~V}$, which ensures the correct operation of the GSM module. Principle electric scheme of the controller is shown in Fig. 7.

\section{THE ALGORITHM OF SYSTEM OPERATION}

Consider the algorithm of the microprocessor signaling device of carbon monoxide presence (Fig. 8).

Block 2: We initialize the carbon monoxide sensor. For correct operation, the sensor should be heated to allow for a chemical reaction. The process of heating and stabilizing the sensor lasts for about a minute. Block 3: We initialize the GSM module. After the power is supplied, the GSM module must connect to the network. Only after that he will be able to send text messages. Block 4-5: The result of the sensor operation is an analog signal that enters the microprocessor. Initially, this signal is converted to digital using an analog-to-digital converter (ADC). Only after that the processor can work with it. Block 6: The resulting numerical value is compared with the value of the dangerous $\mathrm{CO}$ concentration. If the $\mathrm{CO}$ concentration is lower, then go to block 8. If the $\mathrm{CO}$ level exceeds the norm, then go to block 7 .
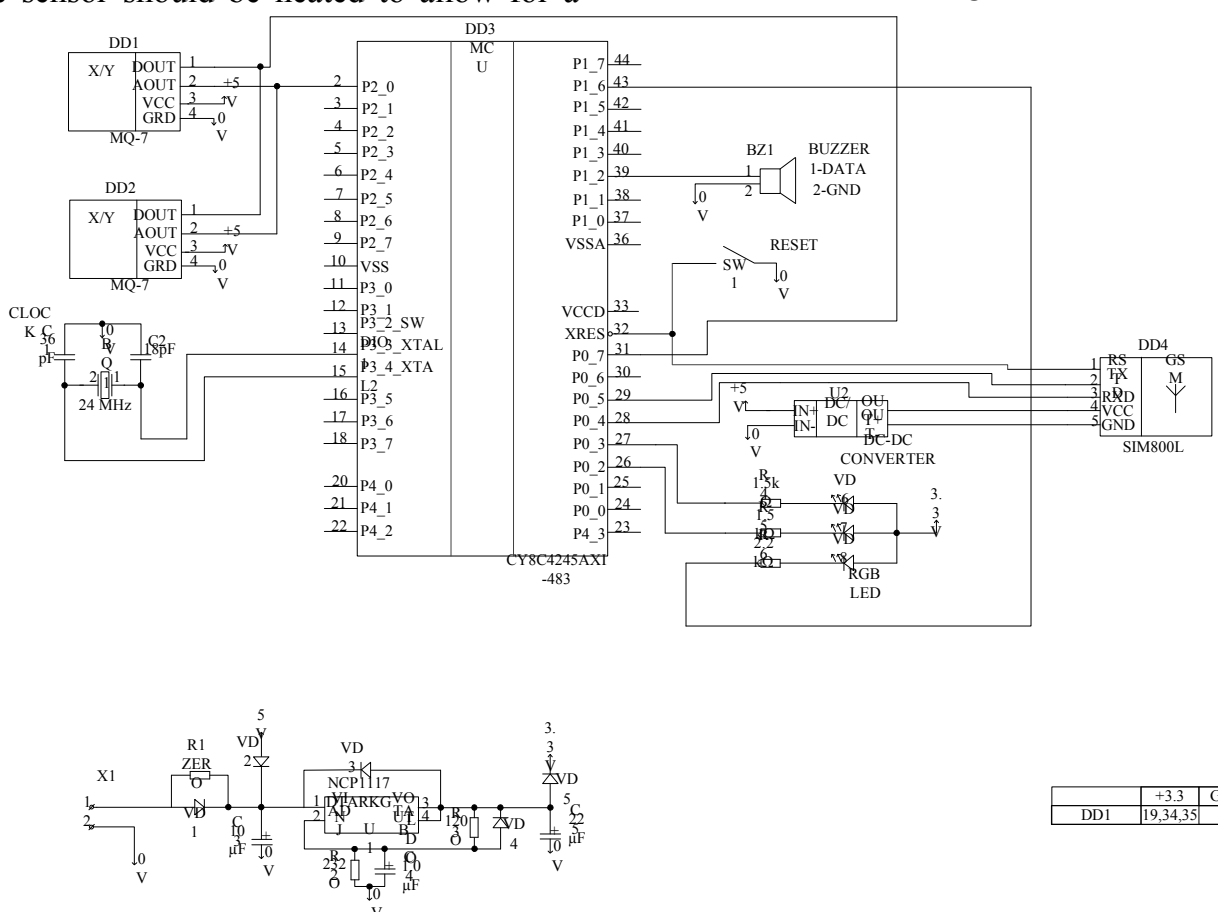

Fig. 7. Principle electric scheme of the system. 


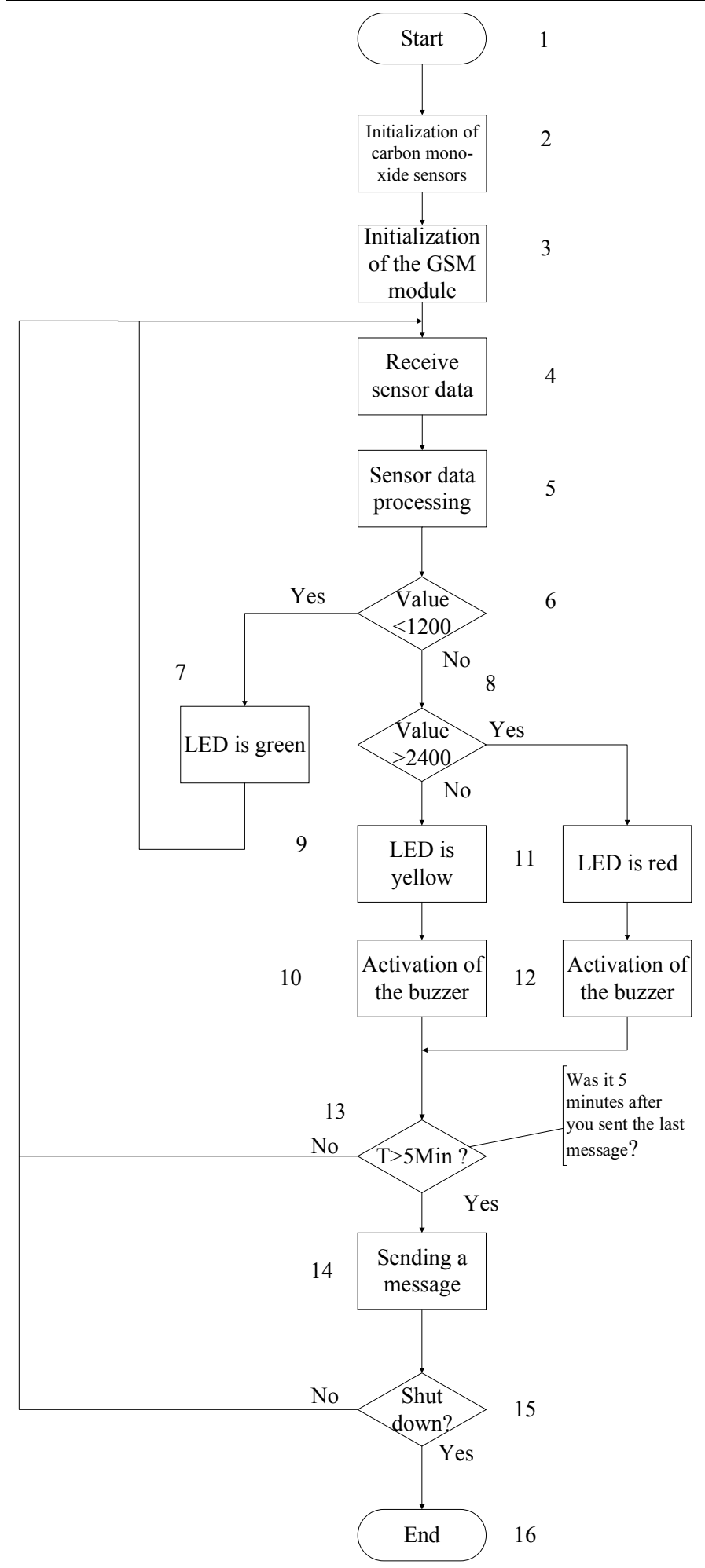

Fig.8. Algorithm of work of the device.

Block 7: The optical indicator on the board is activated. It will glow in green, indicating that the level of carbon monoxide is normal. After that, we go to block 4. Block 8: The resulting digital value is compared with the critical concentration of $\mathrm{CO}$. If the concentration of $\mathrm{CO}$ is less, then go to block 9. If $\mathrm{CO}$ level exceeds the critical level, then go to block 10. Block 9: The optical indicator on the board is activated. It will shine in yellow, indicating that the concentration of carbon monoxide has reached a dangerous level. After that we go to block 11. Block 10: The optical indicator on the board is activated. It will shine in red, indicating that the concentration of carbon monoxide has reached a critical level. After that, we go to block 12. Block 1112: actuated buzzer. He will give a beep that will signal that the concentration of carbon monoxide has exceeded the norm. Depending on the $\mathrm{CO}$ concentration level, the volume of the sound signal will be average or maximum. Block 13: checks are made if 5 minutes have elapsed since the last text message was sent. This is done to prevent frequent message sending. If 5 minutes have passed, then go to block 14. If not, then go to block 4. Block 14: The GSM module sends an SMS message that exceeds the permissible concentration of carbon monoxide in the home. After that we go to block 15. Block 15: Check whether the program is complete. If so, then go to block 16 . If not, then go to block 4. Block 16: shutdown the device.

\section{CONCLUSIONS}

Microprocessor signaling device for the presence of carbon monoxide was developed to control the level of carbon monoxide in the air and, consequently, preserving the life and health of people.

The hardware necessary for controller implementation is determined. On the basis of this, the electric structure is developed and described.

To ensure the functioning of the controller, the main element base was selected and described. The principle of data transfer between components of the controller is considered. On the basis of these data, an electric-functional scheme is developed.

\section{REFERENCES}

[1] Armin Ernst, M.D., and Joseph D. Zibrak, M.D. "Carbon Monoxide Poisoning", N Engl J Med, 1998.

[2] Kales SN, "Carbon Monoxide intoxication", American Family Physician, 1993.

[3] Connie C.W. Hsia, M.D. , "Respiratory Function of Hemoglobin", $N$ Engl J Med, 1998.

[4] Augarten, Stan (1983). The Most Widely Used Computer on a Chip: The TMS 1000. State of the Art: A Photographic History of the Integrated Circuit. New Haven and New York: Ticknor \& Fields. ISBN 0-89919195-9. Retrieved 2009-12-23.

[5] Heath, Steve (2003). Embedded systems design. EDN series for design engineers (2 ed.). Newnes. pp. 11-12. ISBN 9780750655460.

[6] Joe C. King, Jr., "Carbon monoxide sensor", 1997.

[7] Redl, Siegmund M.; Weber, Matthias K.; Oliphant, Malcolm W (February 1995). An Introduction to GSM. Artech House. ISBN 978-089006-785-7

[8] SIM800L Hardware Design. - 2013p. - Shanghai SIMCom Wireless Solutions Ltd. 2013. - 70c.

[9] CY8CKIT-042 PSoC 4 Pioneer Kit Guide. - 2016p. - Cypress Semiconductor. $-132 \mathrm{c}$.

[10] PSoC 4: PSoC 4200 Family Datasheet. - 2016p. - Cypress Semiconductor. $-45 \mathrm{c}$. 